\title{
Clinical evaluation of analytical variations in serum creatinine measurements: why laboratories should abandon Jaffe techniques
}

lefke Drion ${ }^{1 *}$, Christa Cobbaert ${ }^{2}$, Klaas H Groenier ${ }^{1,3}$, Cas Weykamp ${ }^{4}$, Henk JG Bilo ${ }^{1,5,6}$, Jack FM Wetzels ${ }^{7}$ and Nanne Kleefstra ${ }^{1,5,8}$

\begin{abstract}
Background: Non-equivalence in serum creatinine ( $\mathrm{SCr}$ ) measurements across Dutch laboratories and the consequences hereof on chronic kidney disease (CKD) staging were examined.

Methods: National data from the Dutch annual external quality organization of 2009 were used. 144 participating laboratories examined 11 pairs of commutable, value-assigned SCr specimens in the range 52-262 umol/L, using Jaffe or enzymatic techniques. Regression equations were created for each participating laboratory (by regressing values as measured by participating laboratories on the target values of the samples sent by the external quality organization); area under the curves were examined and used to rank laboratories. The $10^{\text {th }}$ and $90^{\text {th }}$ percentile regression equation were selected for each technique separately. To evaluate the impact of the variability in SCr measurements and its eventual clinical consequences in a real patient population, we used a cohort of 82424 patients aged 19-106 years. The SCr measurements of these 82424 patients were introduced in the $10^{\text {th }}$ and $90^{\text {th }}$ percentile regression equations. The newly calculated $\mathrm{SCr}$ values were used to calculate an estimated glomerular filtration rate (eGFR) using the 4-variable Isotope Dilution Mass Spectrometry traceable Modification of Diet in Renal Disease formula. Differences in CKD staging were examined, comparing the stratification outcomes for Jaffe and enzymatic SCr techniques.
\end{abstract}

Results: Jaffe techniques overestimated SCr: 21\%, 12\%, 10\% for SCr target values 52, 73 and $94 \mu \mathrm{mol} / \mathrm{L}$, respectively. For enzymatic assay these values were $0 \%,-1 \%,-2 \%$, respectively. eGFR using the MDRD formula and SCr measured by Jaffe techniques, staged patients in a lower CKD category. Downgrading to a lower CKD stage occurred in $1-42 \%, 2-37 \%$ and $12-78.9 \%$ of patients for the $10^{\text {th }}$ and $90^{\text {th }}$ percentile laboratories respectively in CKD categories $45-60,60-90$ and $>90 \mathrm{ml} / \mathrm{min} / 1.73 \mathrm{~m}^{2}$. Using enzymatic techniques, downgrading occurred only in $2-4 \%$ of patients.

Conclusions: Enzymatic techniques lead to less variability in SCr measurements than Jaffe techniques, and therefore result in more accurate staging of CKD. Therefore the specific enzymatic techniques are preferably used in clinical practice in order to generate more reliable GFR estimates.

Keywords: Calibration, Glomerular filtration rate, Isotope dilution-mass spectrometry, Renal function, Reference standards, Traceability

\footnotetext{
* Correspondence: i.drion@isala.nl

'Diabetes Centre, Isala Clinics, P.O. Box 10400, 8000, GK Zwolle, the Netherlands

Full list of author information is available at the end of the article
} 


\section{Background}

Serum creatinine $(\mathrm{SCr})$ based prediction equations are frequently used in screening and clinical settings in order to estimate the glomerular filtration rate (GFR). The current variability in $\mathrm{SCr}$ measurements affects all estimating equations for GFR, including the MDRD equation. Many automated routine methods for $\mathrm{SCr}$ measurement exceed the desirable imprecision criterion of $\leq 2.2 \%$; therefore, reduction of analytical bias $\leq 3.4 \%$ in creatinine assays by standardization of calibration is needed [1]. It is important to notice that standardization of calibration does not correct for analytical interferences (nonspecificity bias). The bias and nonspecificity problems associated with some of the routine methods must be addressed.

Chronic kidney disease (CKD) staging directly relies on these estimated GFR values. Using accurate SCr measurements is essential, since systematic errors cause unreliable renal function estimates, leading to incorrect drug dose adjustments, misclassifications in CKD staging and incomparability of patient data [2-5].

Since significant interlaboratory variation was observed worldwide, it was internationally confirmed that calibration traceability to higher-order reference methods was needed to realize comparable biochemical measurement results $[2,6,7]$.

Therefore, the European in vitro diagnostics (IVD) directive 98/79/EC, and the laboratory working group of the National Kidney Disease Education Program recommend that in order to improve standardization, clinical laboratory measurements should be traceable to internationally recognized and certified reference materials [8-10]. Since the development of NIST SRM 967 in 2006, a matrix-based IDMS targeted creatinine standard, all essential elements (i.e. reference methods, reference laboratories, and materials) needed to complete the creatinine reference system are in place, according to ISO 17511 [11]. Because the complete traceability train is agreed upon in vitro diagnostic manufactures of creatinine assays in Europe are legally obliged to make their products metrologically traceable, regardless of the method applied.

In this study we examine the degree of variability and interchangeability of SCr measurements across all clinical chemistry laboratories in 2009 in the Netherlands, in order to evaluate the situation after global restandardization, using data from the annual national external quality control program of the Dutch external quality assessment (EQA) organization for clinical chemistry laboratories (Stichting Kwaliteitsbewaking Medische Laboratoriumdiagnostiek, SKML). Subsequently, we investigate in a theoretical model, the impact of the variability in $\mathrm{SCr}$ measurements between laboratories on estimates of GFR using the 4-variable IDMS-traceable
MDRD formula and the consequences hereof on CKD staging of patients, when the data from the SKML are extrapolated to a large cohort of patients.

\section{Methods}

In this cross-sectional study, we evaluate the effect of different SCr assays on SCr levels and CKD classification. EQA data are derived from the 2009 EQA program of the SKML. Annually, the SKML creates 11 pairs of frozen commutable, value assigned serum samples spiked with crystalline creatinine, aliquoted in $1 \mathrm{ml}$ vials. A commutable material reflects the characteristics and properties of native patient samples [2,12]. Valueassignment was performed by a joint committee on traceability in laboratory medicine (JCTLM)-endorsed reference laboratory. Each of the 144 laboratories participating in the EQA program in the Netherlands annually receives a set containing 11 pairs of these commutable samples from the SKML and store them intermittently at $-80^{\circ} \mathrm{C}$. The 11 pairs of EQA-samples cover $\mathrm{SCr}$ values in the entire measuring range: 52-73-94-115136-157-178-199-220-241-262 $\mu \mathrm{mol} / \mathrm{L}$ and form a linear sequence; thus each laboratory received and analyzed, the range mentioned before in twofold over the year. The target values for the $\mathrm{SCr}$ levels are established by a JCTLM listed reference laboratory (Bonn, Germany) using an Isotope Dilution Gas Chromatography/Mass Spectrometry (ID-GC/MS) method [13,14].

Every other week all routine laboratories thawed one of the EQA samples and measured the $\mathrm{SCr}$ concentration applying their routine $\mathrm{SCr}$ methods according to the manufacturer's instructions. $91(63 \%)$ versus 48 (33\%) of the laboratories used a Jaffe or enzymatic method to measure SCr, respectively. 62 (68\%) laboratories using a Jaffe technique applied a modified kinetic Jaffe method; 29 (32\%) used a compensated Jaffe method. Few laboratories used dry chemistry to measure $\mathrm{SCr}$; since this group of laboratories was too small to draw conclusions from $(n=5)$, this group was excluded from further analyses. Companies and instruments included Abbott (Abott Park, Il, USA; Aeroset, Architect), Beckman (Brea, Ca, USA; Synchron, Unicel, LX20, Lxi725), Siemens Healthcare diagnostics (The Netherlands; ADVIA 1650, 1800, 2400), Roche Diagnostics (Mannheim, Germany; Integra, Hitachi, Modular, Cobas, Cobas Integra) and Olympus (Tokyo, Japan; AU 400, 600). In total, 39 different instrument method combinations were used to measure SCr.

Data of the $\mathrm{SCr}$ measurements as measured by the participating laboratories were reported centrally to the SKML and collected in an completely anonymous database.

\section{Variability SCr extrapolated in cohort}

To investigate the impact of the variability in $\mathrm{SCr}$ measurements as found in the national EQA database 
and the eventual clinical consequences hereof in a real patient population, we used an unselected cohort of 82424 patients whose SCr had been measured in 2009 in the Isala Clinics Zwolle, the Netherlands; the details of this population have been described before [15]. In short, $45.3 \%$ of the population was male, age varied from 19-106 years and 38.7\% was older than 65 years old. $\mathrm{SCr}$ in this cohort was measured using an enzymatic technique (modular P Analyzer, creatinine plus assay; Roche Diagnostics, Mannheim, Germany). In order to obtain SCr reference values that are traceable to the reference data from the EQA program for each patient, we requested the results from the 2009 EQA program from the clinical chemistry department, Isala clinics Zwolle. Based on these results we created a regression equation for the Zwolle laboratory (the exact procedure is extensively described in the statistical analyses section), using inverse regression. Subsequently $\mathrm{SCr}$ values as measured in the Zwolle population were introduced in this regression equation in order to calculate the $\mathrm{SCr}$ values traceable to the results of the EQA program for each of the 82424 patients. The GFR using these IDMStraceable $\mathrm{SCr}$ values was estimated using the 4-variable IDMS-traceable MDRD formula [16,17].

\section{Statistical analysis}

We used SPSS version 16.0 (SAS Institute, Cary, NC, USA) and STATA version 11 (StataCorp, College Station, Texas USA) for statistical analyses. All SCr measurements of the laboratories participating in the EQA program were inspected for outliers (truncated at \pm 3 standard deviation (SD)); 3 laboratories were removed from the dataset because more than $50 \%$ of the measurements of these 3 laboratories deviated more than $3 \mathrm{SD}$ from the other laboratories. The target reference values from the linearity sequence of the EQA program served as the reference method against which routine methods to measure $\mathrm{SCr}$ from participating laboratories were compared, by means of relative and absolute bias. The results were displayed in box and whisker plots for each method group. Relative bias is defined as the mean percentage difference [(measured SCr-target value $\mathrm{SCr}$ )/ target value $\mathrm{SCr}] \times$ x 100; absolute bias is defined as the mean difference between $\mathrm{SCr}$ values measured by individual laboratories and $\mathrm{SCr}$ target values; precision is defined as the SD of the absolute bias.

We extrapolated the impact of the non-equivalence in $\mathrm{SCr}$ measures (as derived from the laboratories participating in the EQA program), to our patient cohort of 82424 patients. In order to do so, $\mathrm{SCr}$ values as measured by laboratories participating in the quality assessment program were regressed on the target values of the samples sent by the SKML, so-called inverse regression, for each of the participating laboratories separately. Regression equations for each of the participating laboratories, ( $n=47$ for Jaffe and $n=39$ for enzymatic), who had not changed their technique to measure SCr in 2009, were created. For each of these regression equations (thus for each of the laboratories fulfilling the criteria mentioned above), we calculated an area under the curve (AUC) in the range $73-115 \mu \mathrm{mol} /$ $\mathrm{L}$. The range of $73-115 \mu \mathrm{mol} / \mathrm{L}$ was chosen since especially these values of SCr provide eGFR's around the threshold value of $60 \mathrm{ml} / \mathrm{min} / 1.73 \mathrm{~m}^{2}$, sufficient to classify patients as having CKD stage 3 . Subsequently, the AUC's of all the participating laboratories were ranked in ascending order for the Jaffe and the enzymatic technique separately, in order to establish a $10^{\text {th }}$ and $90^{\text {th }}$ percentile regression equation for each of the techniques. Then, SCr values from our cohort of 82424 patients were inserted in the $10^{\text {th }}$ and $90^{\text {th }}$ percentile regression equations (for the Jaffe technique and the enzymatic technique as appropriate). These 'newly calculated' SCr values were introduced in the appropriate MDRD equations, thus providing $10^{\text {th }}$ and $90^{\text {th }}$ percentile eGFR values. To get an impression from the clinical implications of the variation in $\mathrm{SCr}$ values on CKD staging, we classified the patients according to the K/DOQI guidelines and evaluated the differences in CKD staging when $\mathrm{SCr}$ values were measured by Jaffe or the enzymatic methods [18].

\section{Ethical statement}

No permission was required from the Medical Ethics Committee as our data only included lab result information, which had been obtained from a laboratory database. No personal patient information was included. Permission to use the national 2009 EQA-data was obtained from the SKML. The laboratories in the dataset were anonymous.

\section{Results}

The relative and absolute bias for both Jaffe and enzymatic techniques are shown in Figures 1, 2, 3 and 4. The enzymatic method to measure $\mathrm{SCr}$ produced the least biased results, which were not significantly different from the target values, whereas the Jaffe technique produced the most biased and imprecise results, which differed significantly from the reference values. The Jaffe technique especially tended to overestimate $\mathrm{SCr}$ at low concentrations: $21 \%, 12 \%, 10 \%$ for the $\mathrm{SCr}$ target values 52,73 and $94 \mu \mathrm{mol} / \mathrm{L}$, respectively. The enzymatic method had a small bias that was constant over the entire range of $\mathrm{SCr}$ values. The precision for Jaffe/enzymatic (per reference value) is: 10/3 (52 $\mu \mathrm{mol} / \mathrm{L}), 10 / 3(73 \mu \mathrm{mol} / \mathrm{L}), 7 / 3(94 \mu \mathrm{mol} / \mathrm{L}), 13 / 4$ (115 $\mu \mathrm{mol} / \mathrm{L}), 7 / 5(136 \mu \mathrm{mol} / \mathrm{L}), 8 / 4(157 \mu \mathrm{mol} / \mathrm{L}), 8 / 5$ (178 $\mu \mathrm{mol} / \mathrm{L}), 9 / 5(199 \mu \mathrm{mol} / \mathrm{L}), 10 / 6(220 \mu \mathrm{mol} / \mathrm{L})$, 


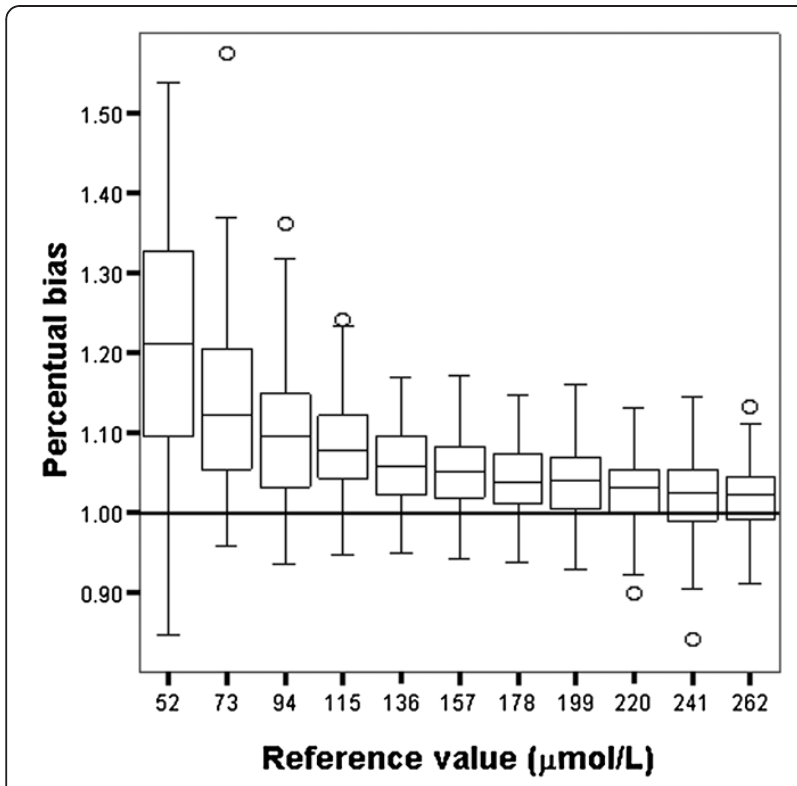

Figure 1 Box and whisker plot showing the percentual bias of the Jaffe technique. Box and whisker plot showing the percentual bias for the Jaffe technique. Interpretation of the vertical axis e.g. 1.1 means a percentual bias of $10 \%$. The box represents the $25^{\text {th }}$, $50^{\text {th }}$ and $75^{\text {th }}$ percentile; the whiskers represent the 5 th and 95 th percentile. The extremes, defined as values more than three times the interquartile range, are the signs above and underneath the whiskers. The grey line represents the $0 \%$ bias line.

$11 / 5(241 \mu \mathrm{mol} / \mathrm{L}), 5 / 2(262 \mu \mathrm{mol} / \mathrm{L})$ for both the Jaffe and the enzymatic method.

The impact of the variability in $\mathrm{SCr}$ measurements on CKD staging is illustrated in Tables 1 and 2. From the tables we can conclude that the differences between the $10^{\text {th }}$ and $90^{\text {th }}$ percentile laboratory are large when a Jaffe technique is used. Downgrading to a lower CKD class was observed using the Jaffe assay for CKD stages: 45$60 \mathrm{ml} / \mathrm{min} / 1.73 \mathrm{~m}^{2}$ (1.1\%, 41.9\%); $60-90 \mathrm{ml} / \mathrm{min} /$ $1.73 \mathrm{~m}^{2}(1.8,36.7 \%)$ and $>90 \mathrm{ml} / \mathrm{min} / 1.73 \mathrm{~m}^{2}(12.3 \%$, $78.9 \%)$, for the $10^{\text {th }}$ and $90^{\text {th }}$ percentile values respectively. When an enzymatic technique was used, the variability resulted in both upward and downward reclassification of CKD stage. Downward reclassification occurred in $2.1-4.1 \%$ of patients, whereas upgrading occurred in $15.6-30.1 \%$ of patients.

\section{Discussion}

The present study shows that interlaboratory nonequivalence in $\mathrm{SCr}$ assays in the Netherlands was still substantial in 2009, notwithstanding the recent international creatinine restandardization effort. The high variability was largely explained by the ongoing use of Jaffe assays for measuring SCr. Compared to the enzymatic assays, the Jaffe assays had a significantly larger bias, especially for $\mathrm{SCr}$ levels in the lower range (reference value range $52-115 \mu \mathrm{mol} / \mathrm{L}$ ). Although relative bias

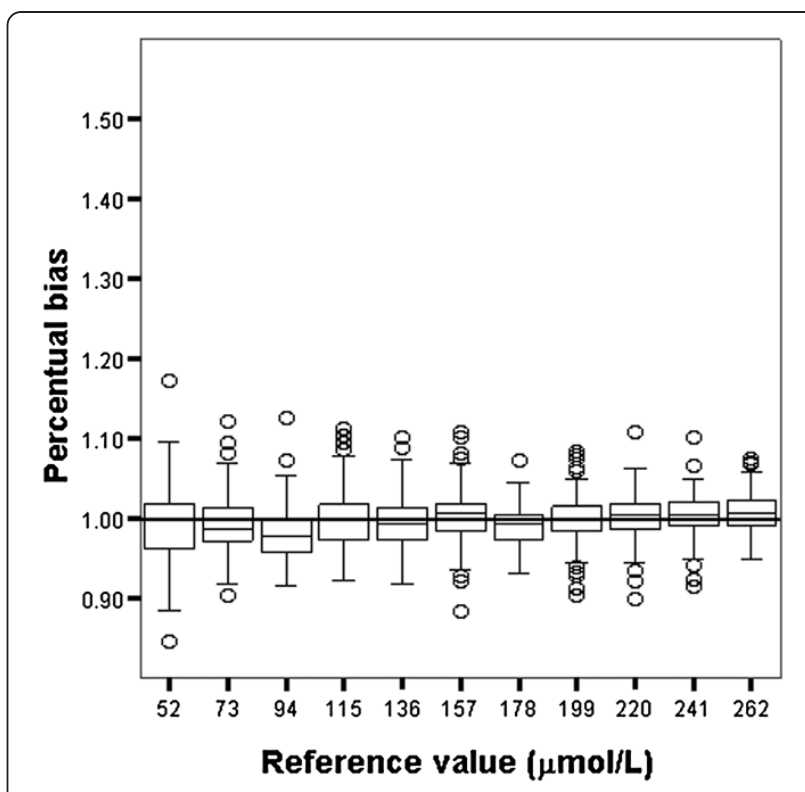

Figure 2 Box and whisker plot showing the percentual bias of the enzymatic technique. Box and whisker plot showing the percentual bias for the enzymatic technique (1). Interpretation of the vertical axis e.g. 1.1 means a percentual bias of $10 \%$. The box represents the $25^{\text {th }}, 50^{\text {th }}$ and $75^{\text {th }}$ percentile; the whiskers represent the 5th and 95th percentile. The extremes, defined as values more than three times the interquartile range, are the signs above and underneath the whiskers. The grey line represents the $0 \%$ bias line.

decreased when SCr reference values were higher, imprecision remained high. It was of course to be expected that Jaffe methods lead to a positive bias compared to the ID-/GC-MS method, and that adjustment for this bias would occur when using the appropriate MDRD equation. This has caused the downgrading of patients to a lower CKD category relevantly more often when a Jaffe technique instead of an enzymatic technique was used, especially in categories $>45 \mathrm{ml} / \mathrm{min} / 1.73 \mathrm{~m}^{2}$ (up to 79\%). In contrast, the use of an enzymatic technique more often resulted in upgrading of the CKD stage, which may be explained by the differences in bias: the Jaffe technique provided higher values of SCr, whereas the enzymatic technique provided slightly lower values.

Ever since $\mathrm{SCr}$ is assessed in clinical practice its accuracy has been debated $[1,7,19]$. Although, SCr measurements are routinely performed, it is one of the most variable laboratory tests [20]. The increasing use of eGFR in clinical practice has renewed the interest on the shortcomings of the SCr methodology [1,21-24]. Since $\mathrm{SCr}$ is the most important variable in the renal function estimation equations, calibration of the creatinine assays is necessary to reduce bias in these formulas. This even lead to a modification of the factor used in the MDRDequation (from 186 to 175 for IDMS traceable creatinine). However, the way this calibration was obtained has been regularly criticized in literature, due to the fact that 


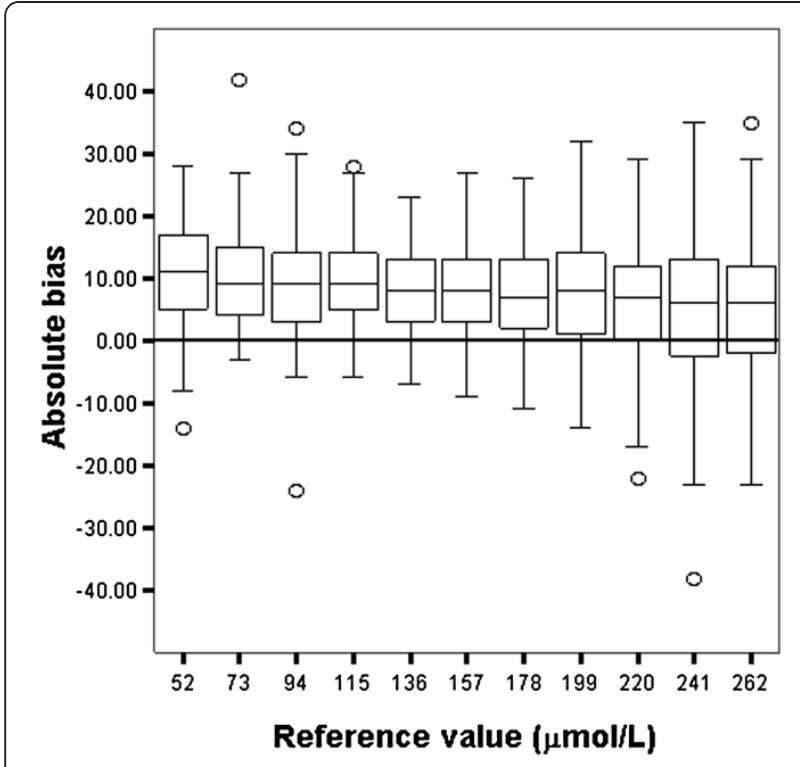

Figure 3 Box and whisker plot showing the absolute bias ( $\mu \mathrm{mol} / \mathrm{L}$ ) for the Jaffe technique. The box represents the $25^{\text {th }}$, $50^{\text {th }}$ and $75^{\text {th }}$ percentile; the whiskers represent the 5 th and 95 th percentile. The extremes, defined as values more than three times the interquartile range, are the signs above and underneath the whiskers. The grey line represents the $0 \mu \mathrm{mol} / \mathrm{L}$ bias line.

the formulas were modified after having recalibrated the Jaffe creatinine to an IDMS traceable enzymatic method, having deleted the intercepts since these were not statistically significant.

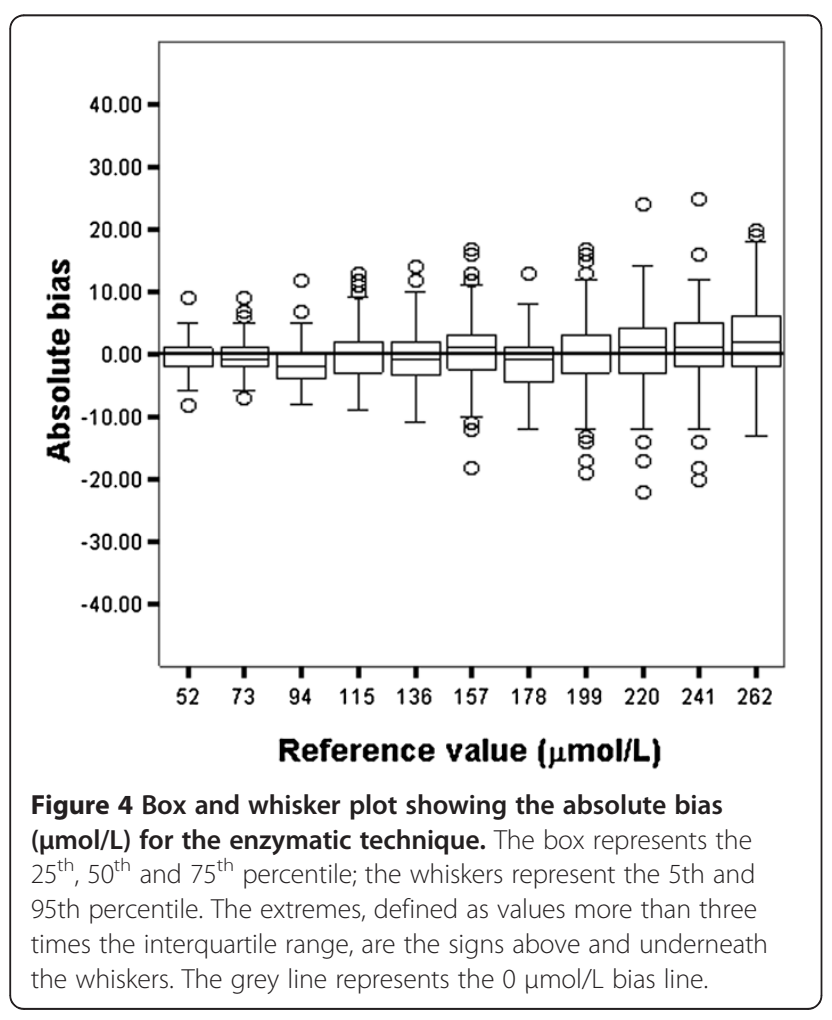

The substantial bias and between laboratory variance as we found in our study, has been shown in various other studies in which data from proficiency testing (PT) and EQA scheme programs were evaluated [7,25,26]. A European trueness verification study of $\mathrm{SCr}$ also showed large interlaboratory variability before the matrix-based SRM 967 standard was available [7]. In our study we would have expected a significantly reduced interlaboratory $\mathrm{CV}$ due to global restandardization on SRM 967. However, despite the European IVD directive with stricter regulations, no improvements compared to earlier studies, in which a method group SD of 2.6$11 \mu \mathrm{mol} / \mathrm{L}$ and a median $\mathrm{CV}$ of $5 \%$ at a SCr concentration of $74 \mu \mathrm{mol} / \mathrm{L}$, had been reached [27]. The failure to realize amelioration of interlaboratory non-equivalence is explained by the fact that standardization does not correct for analytical non-specificity problems, as is the case with the Jaffe method [28,29]. These non-specificity problems concern the measurement of many endogenous and exogenous interfering substances such as protein, glucose and ketones when $\mathrm{SCr}$ is measured using a Jaffe method [28-31]. Despite many attempts to improve the performance characteristics of the Jaffe reaction, non-specificity remained [7]. This leads to overestimation of the true SCr concentration. Calibration traceability cannot solve this problem nor substitute for improvement of suboptimal routine methods.

Although the enzymatic assay to measure $\mathrm{SCr}$ is not free of interference from various substances, it has a better specificity than the Jaffe technique [28]. This was recently confirmed in a multicentre study evaluating IDMS-traceable enzymatic creatinine assays. It showed that the majority of enzymatic methods reached the acceptable total analytical error of $8 \%$ for $\mathrm{SCr}$ values as low as $36 \mu \mathrm{mol} / \mathrm{L}$, when adequately calibrated against IDMS, improving the traceability and standardization of creatinine [32].

Moreover, upgrading in CKD stage as we observed when enzymatic assays were used in the MDRD formula may be less relevant in routine clinical practice than the downgrading to a lower CKD stage as occurs when a Jaffe assay was used to measure SCr. E.g. a patient whose eGFR is $57 \mathrm{ml} / \mathrm{min} / 1.73 \mathrm{~m}^{2}$ (CKD stage 3a) or $62 \mathrm{ml} / \mathrm{min} / 1.73 \mathrm{~m}^{2}$ (CKD stage 2) when a Jaffe respectively an enzymatic assay is used to examine $\mathrm{SCr}$, probably have similar risks regarding end-stage renal disease, all-cause and cardiovascular mortality. From studies comparing the prognosis associated with the two most commonly used equations to estimate GFR (the MDRD and the Chronic Kidney Disease Epidemiology collaboration equation, CKD-EPI) during a long follow-up ( $\geq 7.5$ years) we know that individuals reclassified from CKD stage 3a (eGFR $45-60 \mathrm{ml} / \mathrm{min} / 1.73 \mathrm{~m}^{2}$ ) to no CKD had lower mortality risk than those not reclassified. 
Table 1 Implications for CKD staging when a Jaffe or a standardized serumcreatinine is used

\begin{tabular}{|c|c|c|c|c|c|c|c|c|c|c|c|c|}
\hline & & \multicolumn{11}{|c|}{ MDRD Jaffe $p_{10} / p_{90}$} \\
\hline & & \multicolumn{2}{|c|}{$<30 \mathrm{ml} / \mathrm{min} / 1.73 \mathrm{~m}^{2}$} & \multicolumn{2}{|c|}{$30-45 \mathrm{ml} / \mathrm{min} / 1.73 \mathrm{~m}^{2}$} & \multicolumn{2}{|c|}{$45-60 \mathrm{ml} / \mathrm{min} / 1.73 \mathrm{~m}^{2}$} & \multicolumn{2}{|c|}{$60-90 \mathrm{ml} / \mathrm{min} / 1.73 \mathrm{~m}^{2}$} & \multicolumn{2}{|c|}{$>90 \mathrm{ml} / \mathrm{min} / 1.73 \mathrm{~m}^{2}$} & \multirow[t]{2}{*}{ Total } \\
\hline & & $p_{10}$ & $p_{90}$ & $p_{10}$ & $p_{90}$ & $p_{10}$ & $p_{90}$ & $p_{10}$ & $p_{90}$ & $p_{10}$ & $p_{90}$ & \\
\hline \multirow{6}{*}{$\begin{array}{l}\text { MDRD } \\
\text { standardized }\end{array}$} & $<30 \mathrm{ml} / \mathrm{min} / 1.73 \mathrm{~m}^{2}$ & $2523(99.2 \%)$ & $2543(100 \%)$ & $20(0.8 \%)$ & $0(0 \%)$ & $0(0 \%)$ & $0(0 \%)$ & $0(0 \%)$ & $0(0 \%)$ & $0(0 \%)$ & $0(0 \%)$ & 2543 \\
\hline & $30-45 \mathrm{ml} / \mathrm{min} / 1.73 \mathrm{~m}^{2}$ & $0(0 \%)$ & $678(17.3 \%)$ & $3908(100 \%)$ & $3231(82.7 \%)$ & $1(0 \%)$ & $0(0 \%)$ & $0(0 \%)$ & $0(0 \%)$ & $0(0 \%)$ & $0(0 \%)$ & 3909 \\
\hline & $45-60 \mathrm{ml} / \mathrm{min} / 1.73 \mathrm{~m}^{2}$ & $0(0 \%)$ & $0(0 \%)$ & $90(1.1 \%)$ & $3439(41.9 \%)$ & 8126 (98.9\%) & 4777 (58.1\%) & $0(0 \%)$ & $0(0 \%)$ & $0(0 \%)$ & $0(0 \%)$ & 8216 \\
\hline & $60-90 \mathrm{ml} / \mathrm{min} / 1.73 \mathrm{~m}^{2}$ & $0(0 \%)$ & $0(0 \%)$ & $0(0 \%)$ & $0(0 \%)$ & $736(1.8 \%)$ & $14598(36.7 \%)$ & 39085 (98.2\%) & $25223(63.3 \%)$ & $0(0 \%)$ & (0\%) & 39821 \\
\hline & $>90 \mathrm{ml} / \mathrm{min} / 1.73 \mathrm{~m}^{2}$ & $0(0 \%)$ & $0(0 \%)$ & $0(0 \%)$ & $0(0 \%)$ & $0(0 \%)$ & $0(0 \%)$ & $3448(12.3 \%)$ & 22047 (78.9\%) & $24487(87.7 \%)$ & $5888(21.1 \%)$ & 27935 \\
\hline & & 2523 & 3221 & 4018 & 6670 & 8863 & 19375 & 42533 & 47270 & 24487 & 5888 & 82424 \\
\hline
\end{tabular}

Crosstabulation showing the estimated glomerular filtration rate (GFR) stages when the modification of diet in renal disease equation (MDRD) is calculated with a standardized serumcreatinine versus a serumcreatinine as measured by a p10 (10th percentile) or a p90 (90th percentile) laboratory using a Jaffe technique.

Table 2 Implication for CKD staging when an enzymatic or a standardized serumcreatinine is used

\begin{tabular}{|c|c|c|c|c|c|c|c|c|c|c|c|c|}
\hline & & \multicolumn{11}{|c|}{ MDRD enzymatic $p_{10} / p_{90}$} \\
\hline & & \multicolumn{2}{|c|}{$<30 \mathrm{ml} / \mathrm{min} / 1.73 \mathrm{~m}^{2}$} & \multicolumn{2}{|c|}{$30-45 \mathrm{ml} / \mathrm{min} / 1.73 \mathrm{~m}^{2}$} & \multicolumn{2}{|c|}{$45-60 \mathrm{ml} / \mathrm{min} / 1.73 \mathrm{~m}^{2}$} & \multicolumn{2}{|c|}{$60-90 \mathrm{ml} / \mathrm{min} / 1.73 \mathrm{~m}^{2}$} & \multicolumn{2}{|c|}{$>90 \mathrm{ml} / \mathrm{min} / 1.73 \mathrm{~m}^{2}$} & \multirow[t]{2}{*}{ Total } \\
\hline & & $p_{10}$ & $\mathrm{p}_{90}$ & $p_{10}$ & $p_{90}$ & $p_{10}$ & $\mathrm{p}_{90}$ & $p_{10}$ & $p_{90}$ & $p_{10}$ & $p_{90}$ & \\
\hline \multirow{6}{*}{$\begin{array}{l}\text { MDRD } \\
\text { standardized }\end{array}$} & $<30 \mathrm{ml} / \mathrm{min} / 1.73 \mathrm{~m}^{2}$ & $2483(97.6 \%)$ & $2543(100 \%)$ & $60(2.4 \%)$ & $0(0 \%)$ & $0(0 \%)$ & $0(0 \%)$ & $0(0 \%)$ & $0(0 \%)$ & $0(0 \%)$ & $0(0 \%)$ & 2543 \\
\hline & $30-45 \mathrm{ml} / \mathrm{min} / 1.73 \mathrm{~m}^{2}$ & $0(0 \%)$ & $141(3.6 \%)$ & 3299 (84.4\%) & $3768(96.4 \%)$ & $610(15.6 \%)$ & $0(0 \%)$ & $0(0 \%)$ & $0(0 \%)$ & $0(0 \%)$ & $0(0 \%)$ & 3909 \\
\hline & $45-60 \mathrm{ml} / \mathrm{min} / 1.73 \mathrm{~m}^{2}$ & $0(0 \%)$ & $0(0 \%)$ & $0(0 \%)$ & $338(4.1 \%)$ & 5740 (69.9\%) & $7878(95.9 \%)$ & $2476(30.1 \%)$ & $0(0 \%)$ & $0(0 \%)$ & $0(0 \%)$ & 8216 \\
\hline & $60-90 \mathrm{ml} / \mathrm{min} / 1.73 \mathrm{~m}^{2}$ & $0(0 \%)$ & $0(0 \%)$ & $0(0 \%)$ & $0(0 \%)$ & $0(0 \%)$ & $845(2.1 \%)$ & $28308(71.1 \%)$ & 38976 (97.9\%) & $11513(28.9 \%)$ & $0(\%)$ & 39821 \\
\hline & $>90 \mathrm{ml} / \mathrm{min} / 1.73 \mathrm{~m}^{2}$ & $5(0 \%)$ & $0(0 \%)$ & $0(0 \%)$ & $0(0 \%)$ & $0(0 \%)$ & $0(0 \%)$ & $0(0 \%)$ & $1502(5.4 \%)$ & $27930(100 \%)$ & $26433(94.6 \%)$ & 27935 \\
\hline & & 2488 & 2684 & 3359 & 4106 & 6350 & 8723 & 30784 & 40478 & 39443 & 26433 & 82424 \\
\hline
\end{tabular}

Crosstabulation showing the estimated glomerular filtration rate (GFR) stages when the modification of diet in renal disease equation (MDRD) is calculated with a standardized serumcreatinine versus a serumcreatinine as measured by a p10 (10th percentile) or a p90 (90th percentile) laboratory using an enzymatic technique. 
Moreover, these participants had an equal risk to those classified as no CKD by both formulas [33,34].

Based on the large batch of evidence in literature showing that alkaline picrate methods are inferior methods to measure creatinine, it is time for laboratories to substitute the alkaline picrate method by enzymatic methods. Moreover, if an increasing number of laboratories apply enzymatic techniques, the number of vendors of commercial enzymatic assays will increase, leading to more competition, which will ultimately reduce the costs of these assays. To bring this in a broader perspective, more accurate and precise measurements of SCr will lead to a reduction of the source of error in GFR estimates and thus errors in the staging of renal failure. Considering the number of patients that are misclassified in this study when using an alkaline picrate technique, clinical laboratories should also consider the implications for overall health costs, since patients are referred based on creatinine based estimates of GFR [35].

Although this study is a theoretical analysis, it is one of the few illustrating the consequences of variations in $\mathrm{SCr}$ measurements on GFR estimation and CKD staging for the individual patient. Since the majority of Dutch laboratories is included and we have a large heterogeneous cohort of patients in which we tested our model, we are able to give a good reflection of the consequences it might have for daily clinical practice. Moreover, we have studied creatinine values on 11 different levels against a strong reference method; and the samples used, were all recent instead of remote samples, which are frequently used in other studies. Selection bias may have occurred, since laboratories with too few analyses in the external quality control program were excluded for further analysis in our patient cohort. Moreover, we applied the MDRD formula in a patient cohort with an age range from 19-106 years. This may have introduced bias since, the MDRD has only been validated for patients from 19-70 years, and underestimates the GFR in patients $>70$ years. However, in clinical practice, laboratories automatically report eGFR's each time a creatinine is measured, also in patients older than 70 years, and clinical decision making is often based on these estimates.

\section{Conclusions}

In conclusion, accurate and precise measurements of $\mathrm{SCr}$ are required for a more reliable estimation of GFR as support for reliable clinical decision making. Enzymatic techniques measure $\mathrm{SCr}$ with substantially less variability than Jaffe techniques as compared to ID-MS reference values. This leads to more reliable estimation of GFR and CKD staging. To allow improvement of reliability of eGFR, specific enzymatic techniques to measure $\mathrm{SCr}$ are preferable over unspecific Jaffe techniques.

\section{Abbreviations}

CKD: Chronic Kidney Disease; SCr: Serumcreatinine; GFR: Glomerular Filtration Rate; IVD: In Vitro Diagnostics; JCTLM: Joint Committee on Traceability in Laboratory Medicine; EQA: External Quality Assessment; SKML: Stichting Kwaliteitsbewaking Medische Laboratorium Diagnostiek; IDMS: Isotope Dilution Mass Spectrometry; GCMS: Gas Chromatography Mass Spectrometry; AUC: Area under the curve.

\section{Competing interests}

Jack Wetzels received a consultancy fee from Amgen and Genzyme, received grants from Amgen, Roche, Genzyme; received travel/accommodation/ meeting expenses unrelated to activities listed from Amgen, Genzyme for the ASN 2010. Henk Bilo receives a non-restricted grant for research from Novo Nordisk, is a member of the advisory committee of Merck Sharp \& Dohme. The other authors have no potential conflicts of interest or disclosures relevant to the content of the manuscript to declare.

\section{Authors' contributions}

I.D. researched data, contributed to the discussion and wrote the manuscript; C.C. contributed to the discussion and reviewed/edited the manuscript; K.H.G. participated in the design, researched data, contributed to the discussion; C.W. contributed to the discussion and reviewed/edited the manuscript; H.J.G.B. contributed to the discussion and reviewed/edited the manuscript; J.F.M.W. participated in the design, contributed to the discussion and reviewed/edited the manuscript; N. Kleefstra participated in the design, researched data; contributed to the discussion; reviewed/edited the manuscript. All authors read and approved the final manuscript.

\section{Acknowledgements}

We thank the Stichting Kwaliteitsbewaking Medische Laboratoriumdiagnostiek, for placing the data from their annual quality control program at our disposal. We thank the department of Clinical Chemistry of the Isala Clinics Zwolle for providing the database containing all serumcreatinines that have been measured in 2009 in the Isala Clinics Zwolle.

\section{Author details}

'Diabetes Centre, Isala Clinics, P.O. Box 10400, 8000, GK Zwolle, the Netherlands. ${ }^{2}$ Department of Clinical Chemistry and Laboratory Medicine, Leiden University Medical Center, Leiden, The Netherlands. ${ }^{3}$ Department of General Practice, University Medical Center Groningen, Groningen, The Netherlands. ${ }^{4}$ European Reference Laboratory, Streekziekenhuis Koningin Beatrix, Winterswijk, The Netherlands. ${ }^{5}$ Department of Internal Medicine, University Medical Center Groningen, Groningen, The Netherlands.

${ }^{6}$ Department of Internal Medicine, Isala Clinics, Zwolle, The Netherlands. ${ }^{7}$ Department of Nephrology, Radboud University Nijmegen Medical Center, Nijmegen, The Netherlands. ' Langerhans Medical Research Group, Zwolle, The Netherlands.

Received: 18 January 2012 Accepted: 23 September 2012

Published: 8 October 2012

\section{References}

1. Myers GL, Miller WG, Coresh J, Fleming J, Greenberg N, Greene T, Hostetter T, Levey AS, Panteghini M, Welch M, Eckfeldt JH, National Kidney Disease Education Program Laboratory Working Group: Recommendations for improving serum creatinine measurement: a report from the Laboratory Working group of the National Kidney Disease Education Program. Clin Chem 2006, 52:5-18.

2. Panteghini $M$, Forest JC: Standardization in laboratory medicine: new challenges. Clin Chem Acta 2005, 355:1-12.

3. Coresh J, Eknoyan G, Levey AS: Estimating the prevalence of low glomerular filtration rate requires attention to the creatinine assay calibration. J Am Soc Nephrol 2002, 13:2811-2812.

4. Coresh J, Astor BC, McQuillan G, Kusek J, Greene T, Van Lente F, Levey AS: Calibration and random variation of the serum creatinine assay as critical elements of using equations to estimate glomerular filtration rate. Am J Kidney Dis 2002, 39:920-929.

5. Panteghini M, Myers G, Miller WG, Greenberg N: The importance of metrological traceability on the validity of creatinine measurement as an index of renal function. Clin Chem Lab Med 2006, 44:1287-1292. 
6. Panteghini M: Traceability, reference systems and result comparability. Clin Biochem Rev 2007, 28:97-104.

7. Delanghe J, Cobbaert C, Galteau MM, Harmoinen R, Jansen R, Kruse R, Laitinen P, Thienpont LM, Wuyts B, Weykamp C, Panteghini M: Trueness verification of the current creatinine assays demonstrates a disappointing variability which insufficiently meets changing clinical needs. Clin Chem Lab Med 2007, 45:S59.

8. Dati F: The new European directive on in vitro diagnostics. Clin Chem Lab Med 2003, 41:1289-1298.

9. Lex EU: Directive 98/79 on in vitro medical devices. Off J L 1998, 331:1-37.

10. Müller MM: Implementation of reference systems in laboratory medicine. Clin Chem 2000, 46:1907-1909.

11. Dodder NG, Tai SS, Sniegoski LT, Zhang NF, Welch MJ: Certification of creatinine in a human serum reference material by GC-MS and LC-MS. Clin Chem 2007, 53:1694-1699.

12. Franzini $C$, Ceriotti F: Impact of reference materials on accuracy in clinical chemistry. Clin Biochem 1998, 31:449-457.

13. Stöckl D, Reinauer $\mathrm{H}$ : Candidate reference methods for determining target values for cholesterol, creatinine, uric acid, and glucose in external quality assessment and internal accuracy control. I. Method setup. Clin Chem 1993, 39:993-1000.

14. Thienpont LM, Leenheer AP, Stöckl D, Reinauer H: Candidate reference methods for determining target values for cholesterol, creatinine, uric acid, and glucose in external quality assessment and internal accuracy control. Il. Method transfer. Clin Chem 1993, 39:1001-1006

15. Drion I, Joosten H, van Hateren KJJ, Kleefstra N, Krabbe JG, Wetzels JF, Bilo HJ: Employing age-related cut-off values results in fewer patients with renal impairment in secondary care. Ned Tijdschr Geneeskd 2011, 155:A3091.

16. Levey AS, Bosch JP, Lewis JB, Greene T, Rogers N, Roth D: A more accurate method to estimate glomerular filtration rate from serum creatinine: a new prediction equation. Modification of Diet in Renal disease study group. Ann Intern Med 1999, 130:461-470

17. Levey AS, Greene T, Kusek J, Beck G: A simplified equation to predict glomerular filtration rate from serum creatinine [abstract]. $J \mathrm{Am} \mathrm{Soc}$ Nephrol 2000, 11:155a.

18. National Kidney Foundation: K/DOQI clinical practice guidelines for chronic kidney disease: evaluation, classification, and stratification. Am J Kidney Dis 2002, 39:S1-D246.

19. Lawson N, Lang T, Broughton A, Prinsloo P. Turner C, Marenah C: Creatinine assays: time for action? Ann Clin Biochem 2002, 39:599-602.

20. Joffe M, Hsu C, Feldman HI, Weir M, Landis JR, Hamm L, Chronic Renal Insufficiency Cohort (CRIC) Study Group: Variability of creatinine measurements in clinical laboratories: results from the CRIC study. Am J Nephrol 2010, 31:426-434.

21. Stevens LA, Coresh J, Greene T, Levey AS: Assessing kidney function-measured and estimated glomerular filtration rate. N Engl J Med 2006, 354:2473-2483.

22. Levey AS, Coresh J, Greene T, Stevens LA, Zhang YL, Hendriksen S, Kusek JW, Van Lente F, Chronic Kidney Disease Epidemiology Collaboration: Using standardized serum creatinine values in the modification of diet in renal disease study equation for estimating glomerular filtration rate. Ann Intern Med 2006, 145:247-254.

23. Levey AS, Coresh J, Greene T, Marsh J, Stevens LA, Kusek JW, Van Lente F, Chronic Kidney Disease Epidemiology Collaboration: Expressing the Modification of Diet in Renal Disease Study equation for estimating glomerular filtration rate with standardized serum creatinine values. Clin Chem 2007, 53:766-772.

24. Stevens LA, Manzi J, Levey AS, Chen J, Deysher AE, Greene T, Poggio ED, Schmid CH, Steffes MW, Zhang YL, Van Lente F, Coresh J: Impact of creatinine calibration on performance of GFR estimating equations in a pooled individual patient database. Am J Kidney Disease 2007, 50:21-35.

25. Stöckl D, Libeer JC, Reinauer H, Thienpont LM, De Leenheer AP: Accuracy-based assessment of proficiency testing results with serum from single donations: possibilities and limitations. Clin Chem 1996, 42:469-470.

26. Carobene A, Ferrero C, Ceriotti F, Modenese A, Besozzi M, de Giorgi E, Franzin M, Franzini C, Kienle MG, Magni F: Creatinine measurement proficiency testing: assignment of matrix-adjusted ID GC-MS target values. Clin Chem 1997, 43:1342-1347.
27. European commission - Joint Research Centre: Institute for Reference Materials and Measurements (IRMM). Geel, Belgium: Institute for Reference Materials and Measurements; 2003.

28. Cobbaert CM, Baadenhuijsen $H$, Weykamp CW: Prime time for enzymatic creatinine methods in pediatrics. Clin Chem 2009, 55:549-558.

29. Panteghini M, IFCC Scientific Division: Enzymatic assays for creatinine: time for action. Clin Chem Lab Med 2008, 46:567-572.

30. Cook JG, Association of clinical Biochemists' Scientific and Technica Committee: Factors influencing the assay of creatinine. Ann Clin Biochem 1975, 12:219-232.

31. Cruickshank AM, Ballantyne FC, Shenkin A: Negative interference in a kinetic Jaffe method for serumcreatinine determination. Ann Clin Biochem 1988, 25:112-113.

32. Piéroni L, Delanaye $P$, Boutten $A$, Bargnoux AS, Rozet E, Delatour V, Carlier MC, Hanser AM, Cavalier E, Froissart M, Cristol JP, Société Francaise de Biologie Clinique: A multicentric evaluation of IDMS-traceable creatinine enzymatic assays. Clin Chim Acta 2011, 412:2070-2075.

33. White SL, Polkinghorne KR, Atkins RC, Chadban SJ: Comparison of the prevalence and mortality risk of CKD in Australia using the CKD epidemiology collaboration (CKD-EPI) and modification of diet in renal disease (MDRD) Study GFR estimating equations: the AusDiab (Australian Diabetes, Obesity and Lifestyle) study. Am J Kidney Dis 2010, 55:660-670.

34. Matsushita K, Selvin E, Bash LD, Astor BC, Coresh J: Risk implications of the new CKD epidemiology collaboration (CKD-EPI) equation compared with the MDRD Study equation for estimated GFR: the Atherosclerosis risk in communities (ARIC) study. Am J Kidney Dis 2010, 55:648-659.

35. Panteghini M: The future of laboratory medicine: understanding the new pressures. Clin Biochem Rev 2004, 25:207-215.

doi:10.1186/1471-2369-13-133

Cite this article as: Drion et al:: Clinical evaluation of analytical variations in serum creatinine measurements: why laboratories should abandon Jaffe techniques. BMC Nephrology 2012 13:133.

\section{Submit your next manuscript to BioMed Central and take full advantage of:}

- Convenient online submission

- Thorough peer review

- No space constraints or color figure charges

- Immediate publication on acceptance

- Inclusion in PubMed, CAS, Scopus and Google Scholar

- Research which is freely available for redistribution 